\title{
Confluências Interdisciplinares entre Ciência da Informação e Museologia ${ }^{1}$
}

\author{
Lena Vania Ribeiro Pinheiro \\ IBICT - Instituto Brasileiro de Informação em Ciência e Tecnologia \\ Doutora em Comunicação e Cultura, UFRJ
}

\begin{abstract}
RESUM0: Pesquisa sobre a interdisciplinaridade entre Ciência da Informação e Museologia, tendo como centro de análise as teses e dissertações do Programa de Pós-Graduação em Ciência da Informação (PPGCI) resultado do convênio entre o IBICT e a UFRJ (1970-2000 e a partir de 2008) e do IBICT com a UFF (2003-2008), além de cursos de pós-graduação, pesquisas, grupos de pesquisa, publicações, especialmente periódicos, associação e eventos técnico-científicos. Os resultados mostram indicadores de uma situação ímpar do Brasil, criada e estimulada pelas políticas públicas nacionais e ações acadêmicas, tanto na Ciência da Informação quanto na Museologia, e a presença de estudos que traduzem o fortalecimento e expansão da interdisciplinaridade em diferentes instâncias, sejam teóricas, empíricas ou da prática profissional.
\end{abstract}

PALAVRAS-CHAVE: interdisciplinaridade. Ciência da Informação. Museologia. Programa de PósGraduação em Ciência da informação (PPGCI/IBICT-UFRJ PPGCI/IBICT-UFRJ). Teses e dissertações.

ABSTRACT: Interdisciplinary research about Information Science and Museology having as an analysis center the PPGCI (Graduate Program in Information Science IBICT-UFRJ and IBICT-UFF), graduate courses, researches, research groups, and technical scientific publications, especially journals, association and events, that adopted approach in these areas. The results shows indicators of an unique Brazilian situation created and stimulated by public policies and academic actions, both in Information Science and Museology, and the presence of studies that translated the expansion and strengthening of interdisciplinarity in different instances, whether theoretical, empirical or professional practices.

KEYWORDS: interdisciplinary. Information Science. Museology. Graduate Program in Information Science (PPGCI/IBICT-UFRJ PPGCI/IBICT-UFRJ). Thesis and dissertations.

\section{Introdução: demarcações conceituais da interdisciplinaridade no tempo}

As Ciências Sociais e Humanas, por sua natureza e objeto, trouxeram para as ciências em geral novas abordagens e metodologias, entre as quais a interdisciplinaridade que, com a emergência de novas disciplinas no mundo

\footnotetext{
1 Trabalho desenvolvido no projeto de pesquisa "Correntes teórico-epistemológicas da Ciência da Informação no Brasil e dinâmica de efluentes e afluentes" (2009-2012) (renovado 2012-2016), financiado pelo CNPq (Conselho Nacional de Desenvolvimento Científico e Tecnológico). Doutora em Comunicação e Cultura, UFRJ, IBICT (Instituto Brasileiro de Informação em Ciência e Tecnologia), lenavania@ibict.br.
} 
contemporâneo, impulsionadas também pelas tecnologias, forjaram uma epistemologia multifacetada e híbrida.

A interdisciplinaridade não é uma questão nova, na sua filosofia e ideias. Já estava presente no humanismo grego e no renascimento, quando artistas-cientistas como Leonardo da Vinci, vivenciaram e exerceram práticas interdisciplinares, embora ainda assim não fossem denominadas.

Em Portugal, Olga Pombo apresenta significativa produção teórica sobre interdisciplinaridade. Em uma conferência proferida no Brasil, depois publicada em nosso País, ressalta que "a interdisciplinaridade tem - e sempre teve - um lugar decisivo na criação científica". E ao exemplificar afirma:

como recorda Gilbert Durand, ... os sábios criadores do fim do século XIX e dos dez primeiros anos do século XX (esse período áureo da criação científica, em que se perfilam nomes como os de Gauss, Lobatchevski, Riemann, Poincaré, Hertz, Becquerel, os Curie, Rutherford, Pasteur, Max Plank, Bohr, Einstein), tiveram todos uma formação largamente pluridisciplinar, herdeira do velho trivium (as humanidades) e do quadrivium (os conhecimentos quantificáveis e, portanto, também a música) medievais. (Durand, 1991 apud Pombo, 2005: 9)

Outro exemplo é Whewell, em The philosophy of inductive sciences, do século XIX, que recorreu ao termo consiliente para representar a noção de interdisciplinaridade, assim descrita: "salto conjunto do conhecimento entre e através das disciplinas, por meio da ligação de fatos e de teorias, para criar novas bases explanatórias". (1840 apud Braga. 1999: 9) 
Depois desses exemplos mais espaçados no tempo, começam a surgir, de forma mais sistemática, estudos sobre interdisciplinaridade no interior da epistemologia, disciplina nova na qual se discute também a nova questão.

Assim, alguns autores dedicaram-se a essa temática e no Brasil, há mais de 30 anos, Hilton Japiassu (1976) estuda a interdisciplinaridade, tendo recentemente lançado livro sobre um conceito mais amplo, o de transdisciplinaridade. (Japiassu, 2006).

Olga Pombo (2005), já citada, aponta as dificuldades semânticas e epistemológicas desse termo e de próximos, "mais ou menos equivalentes" ou da "família", como pluridisciplinaridade, multidisciplinaridade e transdisciplinaridade. A autora manifesta a sua preocupação com a "... equivocidade que envolve o conceito de interdisciplinaridade" e assinala: "As suas fronteiras não estão estabelecidas, nem para aqueles que as usam, nem para aqueles que as estudam, nem para aqueles que as procuram definir". Assim, espera contribuir para "proposta de estabilização do sentido da palavra" (Pombo, 2005: 9). Ao mesmo tempo aborda, a partir de Durand, a "passividade monodisciplinar", inibidora do "salto heurístico" de que a ciência moderna necessita, salto esse que, por natureza, sempre esteve e continua a estar "dependente de uma larga informação e cooperação interdisciplinar". (Durand, 1991 apud Pombo, 2005: 9).

Esta discussão inicial é necessária pelo reconhecimento da complexidade e dificuldades demarcatórias conceituais, assim como a inserção histórica da interdisciplinaridade, como pano de fundo para desenvolver o objetivo do presente trabalho: analisar a interdisciplinaridade entre a Ciência da Informação e Museologia, a partir de elementos teóricos e da produção de dissertações e teses do Programa de Pós-Graduação em Ciência da Informação (PPGCI), do IBICT 
(Instituto Brasileiro de Informação em Ciência e Tecnologia) ${ }^{2}$ em parceria com a UFRJ (Universidade Federal do Rio de Janeiro) e com a UFF (Universidade Federal Fluminense) em momentos diferentes. Como desdobramento, o objetivo específico é identificar alguns indicadores desse movimento interdisciplinar em pesquisas e grupos de pesquisa, cursos, disciplinas, publicações, associações e eventos técnicocientíficos das duas áreas no Brasil.

\section{Questões epistemológicas centrais}

Considerando que a interdisciplinaridade foi abordada em publicações anteriores desta autora (Pinheiro, 1995, 1999, 2006, 2007), aqui serão privilegiadas a disciplinaridade, por sua onipresença nos demais conceitos, e a transdisciplinaridade.

Da mesma forma, os conceitos próximos ou assemelhados como pluridisciplinaridade e multidisciplinaridade, além de tipos de interdisciplinaridade, da forma como Japiassu (1976) os categoriza, não serão aqui discutidos: "interdisciplinaridade heterogênea, pseudo-interdisciplinaridade, interdisciplinaridade auxiliar, interdisciplinaridade compósita, interdisciplinaridade unificadora, interdisciplinaridade linear ou cruzada e interdisciplinaridade estrutural". Quando Japiassu (1976: 79-81) define essas categorias está se referindo a graus ou níveis que antecedem a interdisciplinaridade propriamente dita, ainda monólogos, até se consolidar o "diálogo entre disciplinas", representado pela última categoria, a interdisciplinaridade estrutural.

Além deste esclarecimento, reconhecemos, conforme muitos autores, entre eles Clerk (apud Klein, 1996), que disciplinaridade é o "primeiro princípio" sobre o qual

\footnotetext{
20 IBICT inicialmente atuou por mandato acadêmico o convênio com a UFRJ (1970-1981 e 19822000), por um breve período em convênio com a UFF (2003-2008) e a partir do final de 2008, novamente por convênio com a UFRJ, este na modalidade associação ampla.
} 
"tudo é construído" ou é inerente a todas essas palavras pela raiz comum, como Pombo (2005) ressalta em sua "proposta provisória". Para a autora,

... por detrás destas quatro palavras, multi, pluri, inter e transdisciplinaridade, está uma mesma raiz - a palavra disciplina. Ela está sempre presente em cada uma delas. 0 que nos permite concluir que todas elas tratam de qualquer coisa que tem a ver com as disciplinas". Por outro lado, "o sufixo trans supõe um ir além, uma ultrapassagem daquilo que é próprio da disciplina. (Pombo, 2005: 5)

Assim, elegemos apenas um conceito de interdisciplinaridade, para orientar os desdobramentos conceituais posteriores:

\begin{abstract}
Método de pesquisa e de ensino suscetível de fazer com que duas ou mais disciplinas interajam entre si, esta interação podendo ir da simples comunicação das idéias até a integração mútua dos conceitos, da epistemologia, da terminologia, da metodologia, dos procedimentos, dos dados e da organização da pesquisa, ... nova etapa do desenvolvimento do conhecimento científico e de sua divisão epistemológica, e exigindo que as disciplinas científicas, em seu processo constante e desejável de interpenetração, fecundem-se cada vez mais reciprocamente. (Japiassu; Marcondes, 1991:136)
\end{abstract}

Quanto à transdisciplinaridade, a primeira vez que é abordada, em menção de Japiassu (1976), data de mais de 30 anos, cuja criação é por ele atribuída a Piaget, teórico ao qual recorre, e para quem este termo equivaleria a uma etapa posterior e superior "que não se contentaria em atingir interações ou reciprocidade entre pesquisas especializadas, mas que situaria essas ligações no interior de um sistema total, sem fronteiras estabelecidas entre as disciplinas". (Piaget apud Japiassu, 1976:75) 
Em seu livro de 2006, Japiassu destaca o conceito de transdisciplinaridade elaborado no Primeiro Congresso Mundial de Transdisciplinaridade, realizado em Portugal, no ano de 1994: “abordagem científica, cultural, espiritual e social dizendo respeito ao que está entre as disciplinas, através das disciplinas e além de toda a disciplina". Nesta explicitação fica evidente a semelhança com as ideias de Whewell expostas anteriormente, relativas ao termo consiliente.

Outro evento apontado pelo autor foi o Congresso de Lucarno, Suíça, em 1997, promovido pela Unesco e pelo Centre International de Recherches et Études Transdisciplinaires, reunindo Ciência e Educação. O objetivo foi "buscar novas diretrizes para a universidade do próximo século (XXI), pois a atual se encontra ameaçada pela ausência de sentido e por sua recusa em compartilhar os conhecimentos". Japiassu enfatiza a necessidade de contextualizar e globalizar e, remetendo ao título de seu livro - O sonho transdisciplinar e as razões da Filosofia , expressa o que entende por sonho transdisciplinar: “... o lugar geométrico mais ou menos utópico onde deveria manifestar-se o conjunto dessas estratégias, tendo por finalidade a compreensão do mundo presente numa perspectiva utópica de unificação de conhecimentos”. (Japiassu, 2006: 15-16)

\section{Convergências teóricas, empíricas e da prática profissional}

Independentemente de constatações da prática profissional, há indícios de convergências teóricas entre Ciência da Informação e Museologia que se manifestam de diferentes formas: em abordagens, aplicações, aspectos técnicos ou operacionais, acadêmicos e tecnológicos.

A primeira seria o caráter interdisciplinar da Ciência da Informação, admitido desde o seu alvorecer e presente em toda a literatura da área, quer seja apenas na sua menção, sem aprofundamento, ou mesmo a enumeração de uma série de interdisciplinas, algumas mais apontadas e outras, como a Museologia, menos, mas ainda assim presentes em determinadas pesquisas. 
Posteriormente, estudos sobre a interdisciplinaridade da Ciência da Informação ganharam aprofundamento, como os de Saracevic $(1992,1999)$. No artigo de 1992, o autor aborda quatro áreas interdisciplinares à Ciência da Informação, justificando as relações recíprocas: Ciência da Computação, Biblioteconomia, Comunicação e Ciência Cognitiva. Na publicação subsequente, o autor aprofunda as interfaces da Ciência da Informação com as duas primeiras. No caso da Biblioteconomia, a intensidade dessa relação interdisciplinar se manifesta pelo espaço comum entre ambas, "bastante forte", que repousa no "... compartilhamento de suas regras sociais e preocupação geral com a utilização eficaz dos registros gráficos e outros tipos de registros, particularmente pelos indivíduos”. Mas, ao mesmo tempo ressalta as distinções, bem significativas e que o levaram a concluir que “... a Biblioteconomia e Ciência da Informação são dois diferentes campos com fortes relações interdisciplinares, mais do que um campo ou o mesmo campo, ou um sendo um caso especial do outro". (Saracevic, 1999: 1060)

Entre os teóricos também destacamos Wersig (1993), pela relação mais direta de seus trabalhos com museus, a partir da inserção da Ciência da Informação na pósmodernidade e de "interconceitos". 0 autor analisa especificamente o "design de exposições” e conclui: “... os museus não são somente parte integral da Ciência Informação, mas uma parte integral das estratégias pós-modernas de apresentação do conhecimento."

No entanto, pesquisas interdisciplinares entre Ciência da Informação e Museologia quase não aparecem na literatura estrangeira, conforme constataram Lima (2003) em sua tese de doutorado e Moraes (2008) na sua dissertação de mestrado. A situação brasileira se configura como uma exceção.

Em nosso País, estudiosos têm se dedicado a pesquisas interdisciplinares entre Museologia e Ciência da Informação, especialmente aqueles que, graduados em 
Museologia obtiveram pós-graduação em Ciência da Informação (PPGCI/IBICTUFRJ) ou mestres e doutores não-museólogos, mas com atuação em museus e na Museologia. No primeiro caso estão as citadas em Lima (2003) e Moraes (2008) e no segundo, Pinheiro $(1995,1999,2006,2007)$ com pesquisas teóricas e empíricas desenvolvidas há mais de 15 anos, no mapeamento da interdisciplinaridade e aplicações da Ciência da Informação, nas quais a Museologia está presente nas duas relações.

Enquanto a interdisciplinaridade tem sido objeto de inúmeras pesquisas em C\&T, inclusive na Ciência da Informação, as denominadas "aplicações" não são explicitadas, embora relevantes para essa disciplina por outra de suas características, a de perpassar diferentes áreas, na sua horizontalidade ou transversalidade. Quanto à informação especializada, Japiassu (1976) cita brevemente as aplicações, que considera orientadas a profissões, enquanto Pinheiro assim as explica:

\begin{abstract}
As aplicações (contextos, áreas, setores, organismos), isto é, a informação científica, tecnológica, industrial ou artística, ou a aplicação em campos do conhecimento como na Medicina (Informação em Medicina) se mesclam com a interdisciplinaridade propriamente dita são conceitos distintos, embora possam apresentar contribuições interdisciplinares. (Pinheiro, 1990: 176)
\end{abstract}

A interdisciplinaridade da Museologia e Ciência da Informação passa também pela informação em museus, especialmente a informação em arte, nascida de estudos de museus de arte e seus respectivos sistemas e redes de informação, bem como da representação do objeto museológico.

É importante introduzir o pensamento de Ferrez e Bianchini (1987), inovador na época, para as quais o museu é um sistema de informação e os acervos 
museológicos constituem fontes de informação. A ideia, não incorporada às ações de museus há 20 anos, no Brasil e mesmo no exterior, hoje contribui para o reconhecimento da interdisciplinaridade entre Ciência da Informação e Museologia. É oportuno destacar que a primeira autora, Ferrez, é mestre em Ciência da Informação e os seus conhecimentos nessa área propiciaram tal visão.

A definição de Informação em Arte contempla os aspectos interdisciplinares assinalados, uma vez que “... é o estudo da representação do conteúdo informacional de objetos/obras de arte, a partir de sua análise e interpretação. Nesse sentido, a obra artística é fonte de informação", abrangendo "o objeto de arte, documento no seu sentido mais amplo, oriundo de múltiplas manifestações e produções artísticas". (Pinheiro, 2000: 7)

Outro fator de convergência são as tecnologias de informação e comunicação (TIC) que, juntamente com a globalização de todos os setores da sociedade, fomentaram a chamada Sociedade da Informação, posteriormente também denominada Sociedade do Conhecimento. As TIC aproximam diferentes campos do conhecimento, na medida em que as redes facilitam e necessitam, na sua operacionalização, da articulação de pesquisadores e profissionais de distintas formações, com saberes e práticas para atuação conjunta em redes eletrônicas, da mesma forma que proporcionam, mesmo a longas distâncias, a realização de pesquisas inter e transdisciplinares.

Finalmente, uma circunstância acadêmica nacional diz respeito à inexistência de pós-graduação stricto sensu em Museologia até 2006, quando foi implantado o Programa de Pós-Graduação em Museologia e Patrimônio (PPG-PMUS), convênio entre a Universidade Federal do Estado do Rio de Janeiro (UNIRIO) e o Museu de Astronomia e Ciências Afins (MAST) em nível de mestrado. Tornar realidade esse Programa pioneiro da área no Brasil foi uma conquista coletiva possível pela liderança firme e empenho desmedido de sua Coordenadora, Tereza Scheiner 
(UNIRIO), apoiada por Marcus Granato (MAST), Vice-Coordenador. Até então, os museólogos que cursavam a pós-graduação, a faziam em outras áreas, inclusive em Ciência da Informação, neste caso, especialmente no PPGCI.

A produtividade de teses e dissertações que intercruzam Museologia e Ciência da Informação é identificada e analisada no seu conteúdo, no próximo tópico.

\section{Interdisciplinariedade no PPGCI: Ciência da Informação e Museologia}

Tratando-se de produção científica de duas universidades (UFRJ e UFF) e um instituto de pesquisa (IBICT), importa introduzir as distinções entre campo, área e linha de pesquisa, conforme estabelecidos por Amaral (1990):

\footnotetext{
...campo designa o território total cuja investigação o curso pretende operar. Medicina, Filosofia, Comunicação são campos. Área é uma subdivisão do campo, um corte introduzido artificialmente por motivos de estratégia exploratória. Teorias da Comunicação e da Cultura e Tecnologias da Imagem são áreas, como Filosofia Brasileira ou Cirurgia. Existirá linha cada vez que, dentro de uma área (que se caracteriza por uma certa informalidade, no sentido da ausência de uma clara forma individualizadora), certos temas aglutinadores dêem forma a cooperação entre pesquisadores. Estes então se reúnem para, trabalhando em conjunto em torno desses temas, aprofundarem a área e desenvolverem o campo. (Amaral, 1990)
}

Um dos fatores que deve ter contribuído para o desenvolvimento de dissertações e teses interdisciplinares no PPGCI é a existência da linha de pesquisa Teoria, Epistemologia e Interdisciplinaridade da Ciência da Informação, sendo este, o único Programa da área que inclui uma linha dessa natureza. Com a assinatura do novo convênio, em 2009, a área de concentração, Informação e Mediações Sociais e Tecnológicas para o Conhecimento contém, na sua primeira explicitação da ementa, "as questões da interdisciplinaridade". Por outro lado, as linhas de 
pesquisa $^{3}$ foram reduzidas a duas e a primeira "Comunicação, Organização e Gestão da Informação e do Conhecimento" começa pelos "estudos históricos e epistemológicos da Ciência da Informação".

A quantidade de dissertações e teses com o enfoque interdisciplinar entre Ciência da Informação e Museologia e a sua distribuição cronológica são mostradas na Tabela 1.

Tabela 1: Teses e dissertações interdisciplinares do PPGCI (IBICT-UFRJ e IBICT-UFF): Ciência da Informação e Museologia, por distribuição cronológica, 1995-2011

\begin{tabular}{c|c|c|c|c}
\hline \multirow{2}{*}{ Ano } & IBICT- & IBICT-UFRJ & IBICT- & IBICT-UFF \\
& Teses & Dissertaçõe & UFF $^{* *}$ & Dissertaçõe \\
\hline 1995 & - & s & Teses & s \\
\hline 1996 & - & 1 & - & - \\
\hline 1998 & - & 2 & - & - \\
\hline 1999 & - & 1 & - & - \\
\hline 2000 & 1 & - & - & - \\
\hline 2001 & - & 2 & - & - \\
\hline 2002 & 1 & 1 & - & - \\
\hline 2003 & 2 & - & - & - \\
\hline 2004 & 1 & - & - & - \\
\hline 2005 & 1 & - & - & - \\
\hline 2007 & - & - & - & 1 \\
\hline 2008 & - & - & & - \\
\hline 2009 & - & - & & - \\
\hline
\end{tabular}

${ }^{3}$ http://www.ppgci.ufrj.br/index.php/grupos/grupos-de-pesquisa 


\begin{tabular}{c|c|c|c|c}
\hline 2010 & - & - & - & - \\
\hline 2011 & - & - & - & 1 \\
\hline Total & 6 & 9 & 1 & 4 \\
\hline
\end{tabular}

*Mandato e convênio, IBICT-UFRJ (1970-81 e 1982-2000), com últimas turmas selecionadas em 2000 para início em 2001, finalizando mestrado até 2004 e doutorado em 2005.

** Convênio IBICT-UFF (2003-2008)

Quanto à temática dessas dissertações e teses, num total de vinte (Apêndice $A)^{4}$, predomina a informação, objeto de estudo da Ciência da Informação, em distintas abordagens: informação museológica e comunicação (Castro, 1995), informação, museu e alienação (Loureiro, J. M., 1996), informação e discurso museológico (Rocha, 1999) e fluxos da informação em museu de arqueologia (Ribeiro, 2007).

Outras pesquisas enfocaram a Informação em arte: a obra de arte como objeto museológico e fonte de informação (Loureiro, M. L., 1998) e informação em arte e interdisciplinaridade entre Ciência da Informação e Museologia (Lima, 2003), além de duas direcionadas às tecnologias de informação e comunicação: informação e sítios de museus de arte (Miranda, 2001) e museus de arte no ciberespaço (Loureiro, M. L., 2003).

As exposições, de grande relevância para os museus, foram estudadas em quatro pesquisas: duas sobre a exposição e público, ambas de Carvalho, a dissertação enfocando a comunicação e transferência da informação (Carvalho, 1998) e a tese sobre o visitante presencial e o virtual (Carvalho, 2005). A terceira tratando de exposições e interdisciplinaridade (Moraes, 2008) e a última sobre interatividade e ação informacional e comunicacional em museus de ciência (Rocha, 2008).

\footnotetext{
4 É oportuno explicitar que, embora o convênio com a UFRJ-ECO tivesse encerrado em 2000, já haviam sido selecionadas, em outubro de 2000, turmas de mestrado e doutorado para 2001, que foram mantidas assegurando o direito dos alunos. Por essa razão, há casos de teses iniciadas sob o convênio da UFRJ-ECO e concluídas no período do convênio com a UFF.
} 
A divulgação científica e a informação em museus da ciência foi a questão pesquisada em duas dissertações (Cardoso, 2001; Souza, 2007). Ainda sobre museus científicos, mas como campo informacional e de ação hegemônica, foi proposta a representação da ciência e a socialização da informação em tese de doutorado (Loureiro, J. M., 2000).

Finalmente, algumas dissertações e teses não enquadradas nas temáticas já apontadas, e mais específicas em determinadas questões são: museus como espaço do conhecimento e de confiança (Guedes, L., 1995), informação e acervo imagético em museu (Lasmar, 2002), museificação de memórias clandestinas (Castro, 2002), brinquedo como fonte de informação museológica (Guedes, A., 2004) e exposições de um museu itinerante de ciência (Schwenck, 2011).

Consolidando a linha de pesquisa, o IBICT mantém um Grupo de Pesquisa com a mesma denominação - Teoria, Epistemologia e Interdisciplinaridade da Ciência da Informação ${ }^{5}$ - liderado por duas de suas pesquisadoras, exatamente as que concentram maior número de orientações em Museologia e Ciência da Informação, sobretudo a autora deste artigo (Pinheiro), hoje professora convidada do mestrado em Museologia e Patrimônio (UNIRIO-MAST), seguida da Profa. Maria Nélida González de Gómez, com algumas orientações partilhadas entre ambas. Este Grupo de Pesquisa estimula estudos nessa linha, pois seu objetivo é:

\footnotetext{
Favorecer e aprofundar as relações interdisciplinares, sobretudo com as áreas de Comunicação, Ciências da Computação, Epistemologia, Ciências do Conhecimento, Biblioteconomia, Museologia, Arquivologia, entre outras, ao mesmo tempo que mantendo relações permanentes com todos os outros campos do conhecimento que formam de uma ou outra maneira, seu domínio de referência ou aplicação.
}

\footnotetext{
${ }^{5}$ http://dgp.cnpq.br/buscaoperacional/detalhegrupo.jsp?grupo=0026607JCBDLMK
} 
Outro Grupo de Pesquisa do IBICT, intitulado "Comunicação e Divulgação Científica", tendo como líder também a autora do presente artigo e Eloisa Príncipe de Oliveira, ambas do IBICT, inclui a linha de pesquisa "Processos de comunicação e informação em museus. Informação em museus e exposições” e, portanto, fortalece estudos nessa direção, bem como equipes com pesquisadores, professores e alunos oriundos das duas áreas.

A UNIRIO mantém o Grupo de Pesquisa Museu e Museologia6, ao qual se vinculam projetos interdisciplinares, notadamente o de Termos e Conceitos da Museologia, coordenado pela Profa. Diana Farjalla Correia Lima, uma das líderes do Grupo e cujo teor é a fonte de convergência dessas áreas, envolvendo representação e indexação da informação e instrumentos como tesauros e vocabulários controlados.

- Indicadores da interdisciplinaridade entre Ciência da Informação e Museologia em pesquisas empíricas: cursos, publicações e eventos técnico-científicos

A relação interdisciplinar entre Ciência da Informação e Museologia teve suas bases estudadas na tese de Pinheiro (1997), com o mapeamento epistemológico das disciplinas constituintes da Ciência da Informação cujos dados foram atualizados até 2004, tendo como fonte de pesquisa o Arist (Annual Review of Information Science and Technology). Em análises posteriores (Pinheiro, 1999, 2006, 2007) desses resultados empíricos foram identificados os campos do conhecimento com os quais a Ciência da Informação mantém maior ou menor interface interdisciplinar, que vão desde os mais acentuados, como ciência da computação (presente em oito disciplinas da Ciência da Informação) e Biblioteconomia e Administração, que aparecem em cinco disciplinas, além de outras áreas como a Museologia, cujos conhecimentos são incorporados em duas

\footnotetext{
${ }^{6}$ http://dgp.cnpq.br/buscaoperacional/detalhegrupo.jsp?grupo=1697608PY6FR18
} 
disciplinas da Ciência da Informação: Representação da Informação; e Necessidades e Usos de Informação, resultado coerente com os temas das dissertações e teses descritos no tópico 4 deste artigo.

Um estudo coordenado e elaborado pela autora deste artigo em 1995 intitulado "Em busca de um caminho interdisciplinar: proposta de núcleo teórico e prático de disciplinas comuns aos cursos de Biblioteconomia, Museologia e Arquivologia" e atualizado três anos depois (Pinheiro, 1998) foi realizado na UNIRIO, por solicitação do então Decano do Centro de Ciências Humanas e Sociais, Prof. Afonso Celso Mendonça de Paula. Foi constituído um Grupo de Trabalho com professores das três áreas, que discutiram a proposta, especialmente Maria José Wehling, Maria Teresa da Costa Fontoura e Tereza Scheiner. A UNIRIO, por oferecer as três graduações, na ocasião a única universidade com essa característica, apresentava ambiente acadêmico propício a um empreendimento dessa natureza. 0 fundamento dessa proposta foi o "reconhecimento de que as três áreas têm como objeto de estudo a informação, seja um documento no seu significado mais amplo, um testemunho ou registro magnético, na sua essência, o que é "capaz de transformar a estrutura".

Nessa fase, a Unesco discutia o que denominava "harmonização", significando a busca do que essas áreas têm em comum, com o objetivo de facilitar a interlocução. Referia-se às áreas de Biblioteconomia, Arquivologia e Ciência da Informação, não incluindo a Museologia.

\section{- 0 Ensino em Museologia}

A Museologia vem se expandindo no Brasil nos últimos anos, com a criação de cursos de graduação, alguns vinculados a departamentos ou institutos de Ciência da Informação, o que certamente reforçará os laços interdisciplinares entre as áreas. Um exemplo é o curso de graduação em Museologia da Universidade de Brasília (UnB) e a criação da revista Museologia e Interdisciplinaridade, por essa 
mesma Universidade, a ser lançada ainda neste ano de 2012. Antes, o Mestrado em Museologia e Patrimônio, já citado, lançou a revista Museologia e Patrimônio, em 2008, com periodicidade semestral. Esta revista circula em formato eletrônico e adota Sistema Eletrônico de Editoração de Revistas (SEER). O fascículo mais recente é o v.4, no. 2, de 2011.

A expansão de cursos de graduação em Museologia, segundo mapeamento publicado pela Ancib (Lopez et al, 2011) hoje totalizam 14 bacharelados, a maioria criada nos últimos anos. Este crescimento pode estar relacionado ao Programa Reuni (Programa de Apoio aos Planos de Reestruturação e Expansão das Universidades Federais), vinculado ao PDE (Plano de Desenvolvimento da Educação) do MEC (Ministério da Educação), cujo objetivo principal é "ampliar o acesso e permanência na educação superior" (MEC, 2008), para o crescimento do ensino superior público, na sua expansão física, acadêmica e pedagógica. Na verdade, as ações para o Reuni ${ }^{7}$ foram iniciadas em 2003, mas o Programa só foi instituído em 2007, pelo decreto no. 6096, de 14 de abril daquele ano, com previsão para encerramento em 2012.

Importante mencionar o documento da Secretaria de Ensino Superior (Sesu) do MEC que trata dos Referenciais Orientadores para os Cursos Bacharelados Interdisciplinares e Similares ${ }^{8}$.

Quanto à pós-graduação, duas relevantes conquistas acadêmicas certamente contribuirão para a produtividade científica da Museologia: a aprovação do doutorado em Museologia e Patrimônio, no convênio UNIRIO-MAST, iniciado em agosto de 2011 e o mestrado da Universidade de São Paulo (USP), aprovado pela Capes em março de 2012. Esse último, iniciativa de quatro museus daquela

\footnotetext{
${ }^{7}$ http://reuni.mec.gov.br/index.php?option=com_content\&view=article\&id=25\&Itemid=28 ${ }^{8} \mathrm{http}: / /$ reuni.mec.gov.br/images/stories/pdf/novo\%20-\% 20bacharelados\%20interdisciplinares \%20-\%20referenciais\%20orientadores\%20\%20novembro_2010\%20brasilia.pdf
} 
instituição (Museu de Arqueologia e Etnologia, Museu Paulista, Museu de Zoologia e Museu de Arte Contemporânea), onde já funcionava um curso de especialização em Museologia desde 1999.

Tratando-se de um artigo sobre interdisciplinaridade da Ciência da Informação e Museologia, cabe ressaltar que no Programa da UNIRIO-MAST, cinco professores têm pós-graduação, mestrado ou doutorado em Ciência da informação.

Em relação a publicações, pode ser citada a coletânea do IBICT "Interdiscursos da Ciência da Informação: arte, museu e imagem", organizada por Pinheiro e González de Gómez (2000), contendo, entre outros, trabalhos de museólogos pós-graduados em Ciência da Informação: Ana Lucia Siaines de Castro, Diana Farjalla Correia Lima, José Mauro Matheus Loureiro, Maria Lucia de N. Matheus Loureiro e Rosane Maria R. de Carvalho, todos professores do Mestrado em Museologia e Patrimônio no seu começo, exceto Maria Lucia Loureiro.

A participação de museólogos na Ancib (Associação Nacional de Pesquisa e PósGraduação em Ciência da Informação) inicialmente aconteceu por meio de um grupo de trabalho experimental denominado Debates em Museologia e Patrimônio ${ }^{9}$, no Enancib de 2007 em Salvador. Nesse encontro foram apresentados 19 trabalhos, sendo 17 comunicações orais e dois pôsteres, que “... atenderam ao propósito de focalizar relações teóricas e práticas entre o campo museológico / patrimônio e demais domínios do conhecimento e, em especial, as que entrelaçam à Informação e Comunicação." Esta experiência culminou com a criação, proposta pela UNIRIO, do Grupo de Trabalho Museologia, Patrimônio e Informação (GT-9), aprovado no Enancib 2008 em São Paulo, portanto, integrado à Ancib e cuja coordenadora é a Profa. Diana Farjalla Correia Lima, daquela mesma instituição.

\footnotetext{
${ }^{9} \mathrm{http}: / /$ www.enancib.ppgci.ufba.br/prog_dmp.htm
} 
No primeiro ano do GT-9 formalmente instituído, foram aprovadas 15 comunicações, em 2010, 12 e em 2011, 16 comunicações e 1 poster ${ }^{10}$.

Outros espaços institucionais compartilhados pela Museologia e Ciência da Informação são o CNPq e a Capes: no primeiro, a Museologia integra o Comitê de Assessoramento (CA) de Artes, Ciência da Informação e Comunicação e na Capes, na grande área de Ciência Sociais Aplicadas, juntamente com a Ciência da Informação e outras áreas.

Um passo importante para a consolidação e expansão da Museologia no Brasil foi a criação do Ibram (Instituto Brasileiro de Museus) em 2009 pela Lei 11.906, de janeiro de 2009. Entre as suas inúmeras finalidades, a primeira, de acordo com o artigo $3^{0}$ é: "promover e assegurar a implementação de políticas públicas para o setor museológico, com vistas em contribuir para a organização, gestão e desenvolvimento de instituições museológicas e seus acervos”.

A estrutura organizacional do Ibram apresenta três departamentos Departamento de Planejamento e Gestão Interna, Departamento de Difusão, Fomento e Economia dos Museus e Departamento de Processos Museais - e a Coordenação Geral de Sistemas de Informações Museais, desmembrada em coordenações específicas, sendo os dois últimos espaços de estudos de informação.

\section{Considerações Finais: caminhos desbravados e perspectivas}

No presente artigo, por diferentes e diversificados caminhos, epistemológicos e institucionalizadores, foram apontados cursos, pesquisas, teses e dissertações, eventos, sociedades e publicações que deixam claro o movimento interdisciplinar em torno da Ciência da Informação e Museologia no Brasil.

\footnotetext{
${ }^{10}$ Dados informados pela Profa. Diana Farjalla Correia Lima, Coordenadora do GT-9, com base nos relatórios desse Grupo de Trabalho.
} 
Esta condição brasileira é ímpar, uma vez que nos outros países o núcleo de aproximação e estímulo da relação interdisciplinar entre as duas áreas reside em comitês do Icom, sobretudo o Cidoc. Foram identificados poucos movimentos nessa direção como, por exemplo, um fascículo especial e artigos de periódicos publicados eventualmente pelo Jasist Uournal of American Society for Information Science and Technology), o que não significa, necessariamente, abordagem interdisciplinar. Esta quase ausência foi constatada em pesquisas brasileiras nessa temática, especialmente na revisão de literatura de dissertações e teses analisadas neste artigo.

Em nosso País, o foco interdisciplinar da Ciência da Informação e Museologia se origina no IBICT, com a geração de número significativo de dissertações e teses envolvendo Ciência da Informação e Museologia. A concentração de pesquisas nessa linha acontecem no Instituto, com a participação de pesquisadores em Museologia da UNIRIO presentes nos Grupos de Pesquisa do IBICT e da mesma forma e inversamente, pela presença de pesquisadores da Ciência da Informação do IBICT na UNIRIO, em uma verdadeira "fertilização cruzada" de ideias. Por outro lado, na UNIRIO, desde o final dos anos 1990 a preocupação com estudos interdisciplinaridade já se manifestava, sendo, portanto, um solo propício ao ensino e pesquisa interdisciplinar.

Importa ressaltar que esses eventos têm como epicentro centros geradores de conhecimento, podendo transcender as duas áreas estudadas e espraiar-se em outros campos e instâncias. É oportuno lembrar que a busca da transdisciplinaridade está relacionada à crise nas universidades. 0 Congresso de Lucarno sobre transdisciplinaridade, em 1997, mencionado no início deste artigo, teve por motivação maior a busca de novas diretrizes para as universidades neste século, em decorrência das ameaças que enfrenta, pela "ausência de sentido" e "recusa em compartilhar os conhecimentos". Ao pensar essa crise nas 
universidades, Japiassu (2006: 18) recorre à seguinte frase de Péguy: “Quando a poesia está em crise, a solução não consiste em decapitar os poetas, mas em renovar as fontes de inspiração".

Esta metáfora conduz à busca de novas ideias e alternativas para a própria Educação e traz para o centro do debate a exigência de projetos pedagógicos e metodologias interdisciplinares. Assim, pesquisas e estudos introduzidos e sistematizados nesta pesquisa, acenam para atividades acadêmicas e científicas empreendidas nessa tentativa.

Este artigo foi pensado e um esboço apresentado em slides no Grupo Experimental do Enancib 2007. Pela atualização realizada para esse artigo, nota-se acréscimo significativo de cursos, pesquisas, eventos o que, por si só, é indicador da intensificação da interdisciplinaridade entre Ciência da Informação e Museologia e também do próprio crescimento da área de Museologia no Brasil.

Neste novo panorama, é possível prever ou sonhar, como prefere Japiassu, a transdisciplinaridade, inspirada num "novo espírito científico", no qual a "fertilização cruzada" e o "cruzamento de fronteiras" e de pontes epistêmicas sejam um esforço contínuo, dinâmico e renovado, a fim de romper "traçados e limites" disciplinares, embora nestes sustentados, fortalecendo e vitalizando áreas e criando novos territórios inter e transdisciplinares.

\section{REFERÊNCIAS}

AMARAL, Márcio Tavares d'. Nota sobre a organização de um curso de pós-graduação nos moldes de um programa de pesquisa. Boletim Informativo, IBICT/DEP, v.10, n.6, 1990.

BRAGA, Gilda Maria. Prefácio. In: PINHEIRO, Lena Vania Ribeiro (Org.). Ciência da Informação, ciências sociais e Interdisciplinaridade. Brasília, Rio de Janeiro: IBICT/DDI/DEP, 1999. p. 9-10. 
GARCiA, J. C. R. (Org.); TARGINO, M. G. (Org.). Associação Nacional de Pesquisa e PósGraduação em Ciência da Informação (Ancib): reflexão e proposta para dinamização. 1. ed. João Pessoa: Ideia, 2011. v. 1. 153 p.

ENCONTRO NACIONAL DE PESQUISA E PÓS-GRADUAÇAÕ EM CIÊNCI A DA INFORMAÇÃO - Enancib, 8, 2007, Salvador. Debates em Museologia e Patrimônio. Salvador, Ancib, 2007. Disponível em: <http://www.EnAncib.ppgci.ufba.br/prog dmp.htm >. Acesso em: 3 out. 2008. Disponível também em CD-ROM.

FERREZ, Helena Dodd; BIANCHINI, Maria Helena S. Thesaurus para acervos museológicos. Rio de Janeiro: Fundação Nacional Pró-Memória. Coordenadoria de Acervos Museológicos, 1987. 2 v.(Série técnica).

INSTITUTO BRASILEIRO DE INFORMAÇÃO EM CIÊNCIA E TECNOLOGIA (IBICT). Grupo de Pesquisa Comunicação e Divulgação Científicas. Rio de Janeiro; IBICT, 2005. Disponível em: $<$ http://dgp.cnpq.br/buscaoperacional/detalhegrupo.jsp?grupo=00266070N4DU78 $>$. Acesso em: 2 de abril de 2012

INSTITUTO BRASILEIRO DE INFORMAÇÃO EM CIÊNCIA E TECNOLOGIA (IBICT). Grupo de Pesquisa Teoria, Epistemologia e Interdisciplinaridade da Ciência da Informação. Rio de Janeiro, $\quad$ IBICT, $1996 . \quad$ Disponível em: < http://dgp.cnpq.br/buscaoperacional/detalhegrupo.jsp?grupo=0026607JCBDLMK $>$. Acesso em: 2 de abril de 2012

JAPIASSU, Hilton. Interdisciplinaridade e patologia do saber. Rio de Janeiro: Imago, 1976. 221 p. (Série Logoteca).

JAPIASSU, Hilton. $O$ sonho transdisciplinar e as razões da Filosofia. Rio de Janeiro: Imago. 2006. 237p.

JAPIASSU, Hilton; MARCONDES, Danilo. Dicionário básico de Filosofia. 2. ed. Rio de Janeiro: Jorge Zahar Editor, 1991.

KLEIN, Julie Thompson. Crossing boundaries, knowledge disciplinarities and interdisciplinarities. Charlottersville, London: University Press of Virginia, 1996. 281p.

LIMA, Diana Farjalla Correia. Ciência da Informação, Museologia e fertilização interdisciplinar: informação em arte, um novo campo do saber. 2003. Tese (Doutorado em Ciência da Informação) - CNPq/IBICT-UFRJ/ECO, Rio de Janeiro. 2003. Orientadora: Lena Vania Ribeiro Pinheiro.

LOPEZ, A. P. A.; LIMA, D. F. C.; LIMA, M. G. ; GARCIA, J. C. R.; TARGINO, M. das G. Mapeamento das áreas de Biblioteconomia, Ciência da Informação, Arquivologia e Museologia. In: GARCIA, J. C. (Org.) Associação Nacional de Pesquisa e Pós-Graduação em Ciência da Informação (Ancib): Reflexão e proposta para dinamização. João Pessoa: Ideia, 2011, p. 55-80. 
Ministério de Educação e Cultura (MEC). REUNI. Disponível em: http://reuni.mec.gov.br/index.php?option=com content \&view=article\&id=25\&Itemid=28 Acesso em: 2 abr 2012.

MORAES, Julia Nolasco Leitão de. Faces e Interfaces na poesia das coisas: exposições museológicas sob o olhar interdisciplinar da Ciência da Informação e da Museologia. 2008. Dissertação (Mestrado em Programa de Pós Graduação em Ciência da Informação) IBICT - UFF, Rio de Janeiro, 2008. Orientadora: Lena Vania Ribeiro Pinheiro.

PINHEIRO, Lena Vania Ribeiro. Campo interdisciplinar da Ciência da Informação: fronteiras remotas e recentes. In: __ (Org.). Ciência da Informação, Ciências sociais e interdisciplinaridade. Brasília, Rio de Janeiro: IBICT/DDI/DEP, 1999 p. 155-182 (artigo também publicado no México, em Investigación Bibliotecológica, v.12, n.25, p.132-163, 1998).

PINHEIRO, Lena Vania Ribeiro. Campo interdisciplinar da Ciência da Informação: fronteiras remotas e recentes. Investigación Bibliotecológica, v.12, n..25, p.132-163, 1998a.

PINHEIRO, Lena Vania Ribeiro. Ciência da Informação: desdobramentos disciplinares, interdisciplinaridade e transdisciplinaridade. In: GONZALEZ DE GOMEZ, Maria Nelida;

ORRICO, Evelyn Goyannes Dill, (Org.). Políticas de memória e informação: reflexos na organização do conhecimento. Natal: EDUFRN, 2006. p. 111-141.

PINHEIRO, Lena Vania Ribeiro. A Ciência da Informação entre sombra e luz: domínio epistemológico e campo interdisciplinar. 1997. Tese (Doutorado em Comunicação e Cultura) - UFRJ/ECO, Rio de Janeiro, 1997. Orientador: Gilda Maria Braga.

PINHEIRO, Lena Vania Ribeiro. Em busca de um caminho interdisciplinar: proposta de núcleo teórico e prático de disciplinas comuns aos cursos de Biblioteconomia, Museologia e Arquivologia. Rio de Janeiro: UNIRIO, 1998.29 p.

PINHEIRO, Lena Vania Ribeiro. Pilares conceituais para mapeamento do território epistemológico da Ciência da Informação: disciplinaridade, interdisciplinaridade, transdisciplinaridade e aplicações. In: BENTES PINTO, V.; CAVALCANTE, L. E.; SILVA NETO, C. (Org.). Abordagens transdisciplinares da Ciência da Informação: gêneses e aplicações. Fortaleza: Edições UFC, 2007. p. 71-104.

PINHEIRO, Lena Vania Ribeiro. Prefácio. In: PINHEIRO, Lena Vania R., GONZÁLEZ DE GOMÉZ, Maria Nélida (Org.). Interdiscursos da Ciência da Informação: arte, museu, imagem. Rio de Janeiro, Brasília: IBICT/DEP/DDI, 2000. p. 7-14.

POMBO, Olga. Interdisciplinaridade e integração dos saberes. LIINC em Revista, v.1, n.1, p.3-15, mar., 2005. Disponível em: <http://revista.IBICT.br/liinc/index.php/liinc>. Acesso em: 30 out. 2008.

SARACEVIC, Tefko. Information Science. Journal of the American Society for Information Science, v, 50, n.12, p.1051-1063, 1999. 
SARACEVIC, Tefko. Information Science: origin, evolution and relations. In: VAKKARI, Pertti; CRONIN, Blaise, Ed. Conceptions of Library and Information Science; historical, empirical and theoretical perspectives. In: INTERNATIONAL CONFERENCE FOR THE CELEBRATION OF 20TH ANNIVERSARY OF THE DEPARTMENT OF INFORMATION STUDIES, 1991. Proceedings ... University of Tampere, Finland, 1991: London. Los Angeles: Taylor Graham, 1992. p. 5-27.

UNIVERSIDADE FEDERAL DO ESTADO DO RIO DE JANEIRO (UNIRIO). Grupo de Pesquisa Museologia e Patrimônio. 2001. Disponível em: < http://dgp.cnpq.br/buscaoperacional/detalhegrupo.jsp?grupo=1697608PY6FR18 $>$. Acesso em: 2 abr. 2012.

WERSIG, Gernot. Information Science: the study of postmodern knowledge usage. Information Processing and Management. v. 29, n. 2, p.229-240, 1993.

\section{Apêndice A}

Teses e dissertações do Programa de Pós-Graduação em Ciência da Informação (PPGCI) do IBICT, em convênio com a UFRJ e em convênio com a UFF11

1. CARDOSO, Júlio Cesar. Informação, ciência e cotidiano: um estudo sobre a divulgação científica em museus de ciência e tecnologia. 2001. Dissertação (Mestrado em Ciência da Informação) CNPq/IBICT-UFRJ/ECO, Rio de Janeiro, 2001. Orientadores: Geraldo Moreira Prado e José Mauro Matheus Loureiro.

2. CARVAlHO, Rosane Maria Rocha de. Exposição em museus e público: o processo de comunicação e transferência da informação. 1998. Dissertação (Mestrado em Ciência da Informação) - CNPq/IBICT-UFRJ/ECO, Rio de Janeiro, 1998. Orientadora: Lena Vania Ribeiro Pinheiro.

3. CARVALHO, Rosane Maria Rocha de. As transformações da relação museu e público: a influência das tecnologias da informação para o desenvolvimento de um público virtual. 2005. Tese (Doutorado em Ciência da Informação) CNPq/IBICT-UFRJ/ECO, Rio de Janeiro. 2005. Orientadora: Lena Vania Ribeiro Pinheiro.

4. CASTRO, Ana Lúcia Siaines de. Memórias clandestinas e sua museificação: uma prospecção sobre institucionalização e agregação informacional. 2002. Tese (Doutorado em Ciência da Informação) - CNPq/IBICT-UFRJ/ECO, Rio de Janeiro, 2002. Orientadora: Regina Maria Marteleto.

11 As teses e dissertações constituem este apêndice por terem sido utilizadas como material de pesquisa, sendo incluídas nas referências as consultadas para elaboração do artigo. 
5. CASTRO, Ana Lúcia Siaines de. O museu: do sagrado ao segredo. Uma abordagem sobre informação museológica e comunicação. 1995. Dissertação (Mestrado em Ciência da Informação) - CNPq/IBICT-UFRJ/ECO, Rio de Janeiro, 1995. Orientadora: Maria Nélida González de Gómez.

6. GUEDES, Angela Cardoso. Brinquedo: fonte de informação museológica. 2004. Tese (Doutorado em Ciência da Informação). UFRJ/ECO-IBICT, Rio de Janeiro, 2004. Orientadora: Lena Vania Ribeiro Pinheiro.

7. GUEDES, Laura de Oliveira. O museu como espaço de conhecimento e de confiança. 1995. Dissertação (Mestrado em Ciência da Informação) - CNPq/IBICT-UFRJ/ECO, Rio de Janeiro, 1995. Orientadora: Maria de Nazaré Freitas Pereira.

8. LASMAR, Denise Portugal. Estoques de informação: o acervo imagético da Comissão Rondon no Museu do Índio como fonte de informação. 2002. Dissertação (Mestrado em Ciência da Informação) - MCT/IBICT-UFRJ/ECO, Rio de Janeiro, 2002. Orientadoras: Rosali Fernandez de Souza e Isa Maria Freire.

9. LIMA, Diana Farjalla Correia. Ciência da Informação, Museologia e fertilização interdisciplinar: informação em arte, um novo campo do saber. 2003. Tese (Doutorado em Ciência da Informação) - CNPq/IBICT-UFRJ/ECO, Rio de Janeiro. 2003. Orientadora: Lena Vania Ribeiro Pinheiro.

10. LOUREIRO, José Mauro Matheus. Labirinto de paradoxos: informação, museu e alienação. 1996. Dissertação (Mestrado em Ciência da Informação) - CNPq/IBICT-UFRJ/ECO, Rio de Janeiro, 1998. Orientadores: Lena Vania Ribeiro Pinheiro e José Maria jardim.

11. LOUREIRO, José Mauro Matheus. Representação e museu científico: o instrutivo aparelho de hegemonia (ou uma profana liturgia hegemônica). 2000. Tese (Doutorado em Ciência da Informação) - CNPq/IBICT-UFRJ/ECO, Rio de Janeiro, 2000. Orientadora: Heloisa Tardin Christovão.

12. LOUREIRO, Maria Lúcia de Niemeyer Matheus. Museu, informação e arte: a obra de arte como objeto museológico e fonte de informação. 1998. Dissertação (Mestrado em Ciência da Informação) - CNPq/IBICT-UFRJ/ECO, Rio de Janeiro, 1998. Orientadoras: Lena Vania Ribeiro Pinheiro e Maria Nélida González de Gómez.

13. LOUREIRO, Maria Lúcia de Niemeyer Matheus. Museus de Arte no ciberespaço: uma abordagem conceitual. 2003. Tese (Doutorado em Ciência da Informação) - CNPq/IBICT-UFRJ/ECO, Rio de Janeiro, 2003. Orientadores: Lena Vania Ribeiro Pinheiro e Maria Nélida González de Gómez.

14. MIRANDA, Rose Moreira de. Informação e sites de museus de arte brasileiros: representação no ciberespaço. 2001. Dissertação. (Mestrado em Ciência da Informação) - CNPq/IBICTUFRJ/ECO, Rio de Janeiro, 2001. Orientadora: Lena Vania Ribeiro Pinheiro. 
15. MORAES, Julia Nolasco Leitão de. Faces e Interfaces na poesia das coisas: exposições museológicas sob o olhar interdisciplinar da Ciência da Informação e da Museologia. 2008. Dissertação (Mestrado em Programa de Pós Graduação em Ciência da Informação) - IBICT UFF, Rio de Janeiro, 2008. Orientadora: Lena Vania Ribeiro Pinheiro.

16. RIBEIRO, Diego Lemos. A Ciência da Informação em ação: um estudo sobre os fluxos da informação no Museu de Arqueologia de Itaipu. 2007. Dissertação (Mestrado em Ciência da Informação) - IBICT-UFF, Rio de Janeiro, 2007. Orientador: Geraldo Moreira Prado.

17. ROCHA, Luisa Maria Gomes de Mattos. Construindo novos planos de interatividade: proposta técnico-metodológica de ação comunicacional e informacional nas exposições dos museus de ciência. 2008. Tese (Doutorado em Ciência da Informação) - IBICT-UFF, Rio de Janeiro, 2008. Orientadoras: Lena Vania Ribeiro Pinheiro e Maria Nelida González de Gómez.

18. ROCHA, Luísa Maria Gomes de Mattos. Museu, informação: o processo de construção do discurso museográfico e suas estratégias. 1999. Dissertação (Mestrado em Ciência da Informação) - CNPq/IBICT-UFRJ/ECO, Rio de Janeiro, 1999. Orientadores: Regina Maria Marteleto e Rosali Fernandez de Souza.

19. SCHWENCK, Beatriz. Ciência móvel: a mediação informacional nas exposições de um museu itinerante. 2011. Dissertação (Mestrado em Ciência da Informação) - CNPq/IBICT-UFRJ/ECO, Rio de Janeiro, 2011. Orientadora: Regina Maria Marteleto.

20. SOUZA, Daniel Maurício Viana de. Museus de ciência e divulgação científica: a informação sob o crivo da ideologia. 2007. Dissertação (Mestrado em Ciência da Informação) - MCT/IBICT-UFF, Rio de Janeiro, 2007. Orientadores: Geraldo Moreira Prado e José Mauro Matheus Loureiro. 